\title{
Synchronized Nasal Intermittent Positive Pressure Ventilation versus Nasal Continuous Positive Airway Pressure for Prevention of Extubation Failure in Infants after Congenital Heart Surgery
}

\author{
Yi-Rong Zheng, MM, Jian-Feng Liu, MM, Yu-Qing Lei, MM, Hong-Lin Wu, MM, \\ Hua Cao, MD, * Qiang Chen, MD*
}

Department of Cardiac Surgery, and Fujian Key Laboratory of Women and Children's Critical Diseases Research, Fujian Maternity and Child Health Hospital, Affiliated Hospital of Fujian Medical University, Fuzhou, China

\section{ABSTRACT}

Objective: This study aimed to evaluate the application of synchronized nasal intermittent positive pressure ventilation (SNIPPV) in the respiratory weaning of infants after congenital heart surgery.

Methods: We retrospectively analyzed the clinical data of 63 infants who were extubated from mechanical ventilation after congenital heart surgery between January 2020 and September 2020. The data, including demographics, anatomic diagnosis, radiology and laboratory test results, and perioperative variables were recorded. Results: The extubation failure rate within $48 \mathrm{~h}$ after extubation was significantly lower in the SNIPPV group than in the nasal continuous positive airway pressure (NCPAP) group. The $\mathrm{PaO}_{2}$ level and $\mathrm{PaO}_{2} / \mathrm{FiO}_{2}$ ratio within $48 \mathrm{~h}$ after extubation were higher in the SNIPPV group than in the NCPAP group $(P<.05)$. Meanwhile, the $\mathrm{PaCO}$, level within $48 \mathrm{~h}$ was significantly lower in the SNIPPV group $(P<.05)$. Compared with the NCPAP group, the median duration of postoperative noninvasive support and the duration from extubation to hospital discharge were shorter in the SNIPPV group; the total hospital cost was lower in the SNIPPV group. No significant differences were observed between the two groups concerning VAP, pneumothorax, feeding intolerance, sepsis, mortality, and other complications $(P>.05)$.

Conclusion: SNIPPV was shown to be superior to NCPAP in avoiding reintubation after congenital heart surgery in infants and significantly improved oxygenation and reduced $\mathrm{PaCO}$, retention after extubation. Further studies are needed to confirm the efficacy and safety of SNIPPV as a routine weaning strategy.

Received December 7, 2020; accepted Fanuary 3, 2021.

*These authors contributed equally to this work.

Correspondence: Qiang Chen, MD, Department of Cardiac Surgery, Fujian Maternity and Child Health Hospital, Affiliated Hospital of Fujian Medical University, Fuzhou, China; (e-mail: chenqiang2228@163.com).

\section{INTRODUCTION}

Extubation failure rates for mechanically ventilated patients in pediatric cardiac intensive care units (CICUs) range from $5.8 \%$ to 29\% [Benneyworth 2017; Gaies 2015; Harris 2014]. Extubation failure is associated with significant morbidity and mortality and increased the length of ICU stay [Gaies 2015]. Patients with congenital heart disease (CHD) are at high risk of compromised cardiac function, especially during weaning from mechanical ventilation or under the stress of extubation. The use of noninvasive ventilation (NIV) in pediatric cardiac patients as an alternative ventilated support mode has been proved to decrease extubation failure in high-risk infants [Richter 2019]. To date, nasal continuous positive airway pressure (NCPAP) is the most widely used assisted ventilation modality for infants after extubation [Lemyre 2016]. Nasal intermittent positive pressure ventilation (NIPPV) has been described as another method of weaning infants from mechanical ventilation in different pediatric or neonatal settings [Lemyre 2016; Essouri 2005]. However, NIPPV has the limitation of not being synchronized with the patient's breathing efforts. Compared with other non-synchronized NIV modalities, synchronized nasal intermittent positive pressure ventilation (SNIPPV) has been demonstrated to reduce breathing effort, improve oxygenation, and optimize patient-ventilator interactions [Chang 2011; Bhandari 2007]. We hypothesize that the physiological advantages of SNIPPV will lead to earlier successful initial extubation. To date, no study has directly compared SNIPPV and NCPAP in terms of their ability to prevent reintubation after congenital heart surgery in infants. The purpose of this study was to investigate the efficacy and safety of SNIPPV and NCPAP in postoperative extubation in infants with CHD.

\section{MATERIALS AND METHODS}

\section{Patient Characteristics}

We performed a retrospective cohort study of all CHD infants aged less than three months admitted to our center between January 2020 and November 2020 who received cardiac surgery (with or without cardiopulmonary bypass). SNIPPV became available in our CICU in June 2020. We 
identified patients from the SNIPPV era (June 2020 to November 2020) and compared them to historical controls when only NCPAP was available (January 2020 to May 2020) to decrease selection bias. Choice of postextubation NIV ventilation method was made prior to extubation, based on physician's preference. The inclusion criteria included those postoperative patients with satisfactory anatomical correction and stable hemodynamics. The exclusion criteria included postoperative extracorporeal cardiopulmonary support, tracheostomy tube cannulation before surgery, parents' decision not to participate, discharged from the CICU before extubation, or death before extubation. If patients achieved the following criteria, we would consider extubation: hemodynamic stability; the fraction of inspired oxygen $\left(\mathrm{FiO}_{2}\right) \leq 40 \%$; peak inspiratory pressure (PIP) $\leq 18 \mathrm{cmH}_{2} \mathrm{O}$; positive end-expiratory pressure (PEEP) $2 \sim 4 \mathrm{cmH}_{2} \mathrm{O}$; and the arterial blood gases (ABGs) indicating that: partial pressure of carbon dioxide in arterial blood $\left(\mathrm{PaCO}_{2}\right)<50 \mathrm{mmHg}$, partial pressure of oxygen in arterial blood $\left(\mathrm{PaO}_{2}\right)>70$ $\mathrm{mmHg}, \mathrm{pH}>7.30$, and lactic acid $<2.0 \mathrm{mmol} / \mathrm{L}$. The local ethics committee approved this study and a summary of the data collection methods. All procedures performed in studies involving human participants followed the institutional and national research committee's ethical standards and the Declaration of Helsinki and its later amendments, or comparable ethical standards.

\section{Respiratory Modalities and Equipment}

After extubation, either SNIPPV or NCPAP would be connected to infants using silicone nasal prongs. SNIPPV was delivered through a time-cycled, pressure-limited, and continuous-flow ventilator (Sophie, Fritz Stephan, Gackenbach, Germany), which detected the inspiratory effort of the infants utilizing the Graseby abdominal capsule-triggering device (Fritz Stephan, Gackenbach, Germany). The ventilator's initial parameters were as follows: $\mathrm{FiO}_{2}$ regulated from 0.21 to 0.60 , PIP regulated from 15 to $20 \mathrm{cmH}_{2} \mathrm{O}$, RR regulated from 20 to 30 times/min, and PEEP regulated from 2 to $6 \mathrm{cmH}_{2} \mathrm{O}$. Infants assigned to NCPAP were initiated using a PEEP of $3 \mathrm{~cm} \mathrm{H} 2 \mathrm{O}$ (subsequent regulation range, 3-6 $\mathrm{cm} \mathrm{H}_{2} \mathrm{O}$ ) with a nasal CPAP-system (Infant Flow System, EME, UK), with $\mathrm{FiO}_{2}$ regulated from 0.21 to 0.60 . Extubation failure was defined as reintubation within $48 \mathrm{~h}$ after the first planned extubation. Indications for reintubation were based on the following criteria: upper airway obstruction, respiratory dysfunction (severe hypoxemia or hypercapnia), hemodynamic instability, loss of consciousness, weak or stopped breathing, and thoracic active hemorrhage [Lu 2010]. For infants with failed extubation, we would adopt synchronized intermittent mandatory ventilation (SIMV) mode for respiratory support. To avoid gastric/ intestinal dilatation, an oral gastrointestinal catheter was used in both groups during the intervention and evacuated regularly. ABGs were monitored every $6 \mathrm{~h}$, and all infants had continuous pulse oximetry monitoring. Dexamethasone was administered intravenously at $0.5 \mathrm{mg} / \mathrm{kg}$ per dose every $12 \mathrm{~h}$ for four doses, $24 \mathrm{~h}$ before extubation for every infant in each group to prevent laryngeal edema and stridor.

\section{Data Collection and Definitions}

We conducted a detailed retrospective review of all medical records. The data collection included demographics, anatomic diagnosis, radiology and laboratory test results, and perioperative variables. The primary outcomes included the reintubation rate within $48 \mathrm{~h}$ of extubation, and the reasons for the failure (hypoxemia, hypercapnia, and heart failure) were analyzed. Besides, we analyzed the changes in ABGs ( $\mathrm{pH}$ value, $\mathrm{PaO}_{2}, \mathrm{PaCO}_{2}$, and $\mathrm{PaO}_{2} / \mathrm{FiO}_{2}$ ratio) before and after the treatment in the two groups. For secondary outcomes, the differences in postoperative NIV support time, duration from extubation to hospital discharge, time to full gastrointestinal feeding, postoperative length of stay (LOS), total hospital costs, and total hospital LOS were analyzed. After treatment, complications and short-term outcomes, such as ventilator-associated pneumonia (VAP), sepsis, mortality, pneumothorax, diaphragm and vocal cord paresis, feeding intolerance, and gastroesophageal reflux, were also evaluated in the two groups of children. Pulmonary hypertension was defined as a mean pulmonary artery pressure of $25 \mathrm{mmHg}$ or higher [Badesch 2009]. Inotropes and vasopressors were used to maintain hemodynamic stability. The vasoactive-inotropic score (VIS) was calculated as: VIS $=$ dopamine dose $(\mathrm{g} / \mathrm{kg} /$ $\mathrm{min})+$ dobutamine dose $(\mathrm{ug} / \mathrm{kg} / \mathrm{min})+100 \times$ epinephrine dose $(\mathrm{ug} / \mathrm{kg} / \mathrm{min})+10 \times$ milrinone dose $(\mathrm{ug} / \mathrm{kg} / \mathrm{min})+10,000$ $\times$ vasopressin dose (units $/ \mathrm{kg} / \mathrm{min})+100 \times$ norepinephrine dose (ug/kg/min) [Gaies 2010].

\section{Statistical Analysis}

SPSS software version 22.0 was used for the statistical analysis. Independent continuous variables were presented as the mean \pm standard deviation (SD) and analyzed by t tests. Counts and percentages described enumeration data. For testing differences between categorical variables, Pearson chi-square test or Fisher exact analysis was used. The MannWhitney $U$ test was applied for non-normally distributed data. A $P$ value of less than .05 was regarded as statistically significant.

\section{RESULTS}

\section{Patient Characteristics}

During the study period, 63 infants who underwent congenital heart surgery met the inclusion criteria for analysis, including 36 males and 27 females. We recruited 38 infants with ventricular septal defect, 9 infants with patent ductus arteriosus, 8 infants with pulmonary stenosis, 3 infants with coarctation of aorta, 3 infants with total anomalous pulmonary venous connection and 2 infants with interrupted aortic arch. In these infants, 33 were supported with SNIPPV, and 30 were supported with NCPAP after extubation. There were no significant differences between the two groups in terms of age, sex, weight at surgery, preoperative pneumonia, preoperative respiratory failure, pulmonary hypertension, inhaled nitric oxide treatment at extubation, sedation at extubation, VIS at extubation and cardiopulmonary bypass (CPB) time (Table 1). The clinical characteristics at the time of extubation 
Table 1. Baseline Characteristics

\begin{tabular}{|c|c|c|c|}
\hline $\operatorname{Sex}(M / F)$ & $18 / 15$ & $16 / 14$ & 1.000 \\
\hline Age at surgery, days, mean $\pm S D$ & $43.0 \pm 11.1$ & $46.2 \pm 11.9$ & .280 \\
\hline Weight at surgery, $\mathrm{kg}$, mean $\pm \mathrm{SD}$ & $4.5 \pm 0.7$ & $4.6 \pm 0.8$ & .500 \\
\hline Preoperative respiratory failure, $\mathrm{n}(\%)$ & $5(15)$ & $3(10)$ & .710 \\
\hline Pulmonary hypertension, $\mathrm{n}(\%)$ & $17(52)$ & $19(63)$ & .446 \\
\hline \multicolumn{4}{|l|}{ Disease } \\
\hline Ventricular septal defect & 20 & 18 & .943 \\
\hline Patent ductus arteriosus & 4 & 5 & \\
\hline Interrupted aortic arch & 1 & 1 & \\
\hline Surgery with cardiopulmonary bypass, $\mathrm{n}(\%)$ & $28(85)$ & $26(87)$ & 1.000 \\
\hline $\mathrm{CPB}$ time, min, mean $\pm \mathrm{SD}$ & $135 \pm 49$ & $137 \pm 30$ & .855 \\
\hline Sedation (midazolam dose), $\mu \mathrm{g} / \mathrm{kg} / \mathrm{min}$, mean $\pm \mathrm{SD}$ & $3.6 \pm 2.1$ & $3.7 \pm 2.5$ & .772 \\
\hline Inhaled NO at extubation, $\mathrm{n}(\%)$ & $5(15)$ & $6(20)$ & .744 \\
\hline Vasoactive-Inotropic Score at extubation, median (IQR) & $7.5(5-7.5)$ & $7.0(5-8.5)$ & .840 \\
\hline
\end{tabular}

Data reported as number and percentage, mean \pm standard deviation, or median and interquartile range. CPB indicates cardiopulmonary bypass; IQR, interquartile range.

Table 2. Clinical Characteristics at the Time of Extubation

\begin{tabular}{lccc}
\hline & SNIPPV $(\mathrm{n}=33)$ & NCPAP $(\mathrm{n}=30)$ & $P$ \\
\hline Duration of mechanical ventilation, days & $1.5(1.1,2.3)$ & $1.8(1.3,2.6)$ & .285 \\
$\mathrm{PIP}, \mathrm{cmH}_{2} \mathrm{O}$ & $15(14,17)$ & $16(13,17)$ & .180 \\
$\mathrm{PEEP}, \mathrm{cmH}_{2} \mathrm{O}$ & $3(2-5)$ & $3(2-4)$ & .673 \\
$\mathrm{MAP}, \mathrm{cmH}_{2} \mathrm{O}$ & $6(6.0,7.5)$ & $7(6.5,8.0)$ & .853 \\
$\mathrm{OI}$ & $6.5(5.2,7.6)$ & $6.2(4.5,7.2)$ & .677 \\
$\mathrm{FiO}_{2}, \%$ & $0.30(0.25,0.38)$ & $0.29(0.25,0.36)$ & .849 \\
$\mathrm{PaO}_{2}, \mathrm{mmHg}$ & $71.5(65.6,76.3)$ & $69.7(63.5,76.9)$ & .183 \\
$\mathrm{PaCO}_{2}, \mathrm{mmHg}$ & $42.1(39.6,47.3)$ & $43.8(38.5,48.2)$ & .090 \\
\hline
\end{tabular}

Data reported as number and percentage, mean \pm standard deviation, or median and interquartile range. PIP indicates peak inspiratory pressure; PEEP, positive end-expiratory pressure; MAP, mean airway pressure; OI, oxygen index,

were similar between the two groups, which are shown in Table 2.

\section{Primary Outcomes}

The rate of extubation failure within $48 \mathrm{~h}$ after extubation was significantly lower in the SNIPPV group than in the
NCPAP group (extubation failure: 2:32 vs 8:32, respectively; $P<.001)$. The main reasons for extubation failure in the two groups were hypercapnia $(n=5)$, hypoxemia $(n=4)$, and heart failure $(\mathrm{n}=1)$. Moreover, $\mathrm{ABG}$ indexes, including $\mathrm{PaO}_{2}$ and the $\mathrm{PaO} / \mathrm{FiO}_{2}$ ratio, were higher in the SNIPPV group than in the NCPAP group within $48 \mathrm{~h}$ after extubation $(P<.05)$ 
(Table 3). Nevertheless, the $\mathrm{PaCO}_{2}$ levels within $48 \mathrm{~h}$ were significantly lower in the SNIPPV group than in the NCPAP group $(P<.05)$ (Table 3$)$. There was no significant difference in $\mathrm{PH}$ between the two groups $(P>.05)$.

\section{Secondary Outcomes}

The median SNIPPV duration was 2.3 days (range 1.3-4.5 days), which was shorter than that for NCPAP (4.0 days; range 2.8-6.4 days) $(P=.013)$. Moreover, the postoperative LOS and the duration from extubation to hospital discharge were found to be significantly shorter in the SNIPPV group than in the NCPAP group: 12.5 days (range 9.0-16.7 days) vs 15.7 days (range 13.0-21.7 days) and 8.2 days (range 5.1-11.2 days) vs 11.3 days (range 7.5-16.8 days), respectively $(P<.05)$ (Table 4). The total hospitalization expense of infants in the SNIPPV group was $\$ 9790 \pm \$ 3530$, which was significantly lower than that of the NCPAP group $(\$ 12133 \pm \$ 4582)(P=.031)$. We did not find significant differences between the two groups for other secondary outcomes, including the incidence of VAP, sepsis, perioperative mortality, pneumothorax, diaphragm paresis, vocal cord paresis, feeding intolerance, gastroesophageal reflux and time to full gastrointestinal feeding after surgery (Table 4).

\section{DISCUSSION}

With the development of noninvasive ventilation technology, new noninvasive respiratory support modes, such as NIPPV, bilevel positive airway pressure (BiPAP), SNIPPV, nasal high-frequency ventilation (NHFV), and nasal neurally adjusted ventilatory assist (NNAVA), have been gradually applied in clinical practice. Related studies confirmed that a significant aspect of these new noninvasive ventilation methods is that they could provide better-assisted ventilation effects, improve alveolar ventilation, reduce respiratory function, and increase gas exchange efficiency compared with the traditional NCPAP mode [Chen 2019; Fedor 2017; Parashar 2019].

In this study, we found that SNIPPV was more effective than NCPAP in reducing the rate of reintubation, and the duration of respiratory support was shorter in the SNIPPV group. Moreover, compared with NCPAP, we found that the application of SNIPPV after extubation had apparent effects on improving oxygenation and reducing the retention of $\mathrm{PaCO} 2$. Therefore, SNIPPV could effectively improve respiratory function, which was beneficial to those patients who underwent cardiac surgery. This result was consistent with the conclusions reported in other studies [Tao 2016; Sai 2009; Zhou 2015; Lemyre 2017].

Extubation failure after congenital heart surgery is associated with prolonged hospital stay and mortality [Richter 2019]. The entire extubation failure rate was $15.6 \%$ in this study, which was related to younger age, more severe preoperative lung infections, and cardiac surgeries of the enrolled infants. After weaning from mechanical ventilation in infants following cardiovascular surgery, NCPAP assisted ventilation was usually adopted for the transition. NCPAP could increase functional residual capacity and prevent alveolar collapse, thereby improving pulmonary oxygenation and reducing intrapulmonary shunts [Polin 2002]. However, 25\%-34\% of children supported with NCPAP still needed reintubation due to low oxygen pressure, tachypnea, or severe $\mathrm{CO} 2$ retention, which might increase attendant risks and expense [Tao 2016; Sai 2009]. Lemyre and his team evaluated three randomized trials and compared NIPPV (synchronous or asynchronous mode) with NCPAP in premature infants after extubation [Lemyre 2017]. They showed that NIPPV was more effective than NCPAP in reducing the need for reintubation within one week. Bhandari et al also found that NIPPV was more conducive to extubation than NCPAP [Bhandari 2010]. Compared with NCPAP, SNIPPV could reduce the forced inhalation of infants with respiratory distress, and due to the intermittently higher positive pressure in the nasopharynx, it could promote the expansion of the upper airway. Moreover, the additional peak pressure provided by SNIPPV could reduce the work of the respiratory muscles, increase mean airway pressure and tidal volume, improve lung capacity, and increase gas exchange [Barrington 2001]. We also found that SNIPPV significantly reduced the rate of reintubation and improved ABG parameters after extubation. This result might be associated with the fact that SNIPPV increased intermittent positive pressure at a particular frequency based on NCPAP to increase average airway pressure and tidal volume [Chang 2011]. Also, the synchronized delivery of NIPPV according to the infant's breathing efforts could cause changes in ventilator pressure following the infants' physiological status. In theory, this synchronous mode could synchronize the pressure exerted by the ventilator with the patient's spontaneous inhalation during assisted ventilation so that the gas could enter the lower respiratory tract to the lungs more effectively, which could effectively prevent alveolar collapse, expand the small airways, and decrease work of breathing [Zhou 2015; Bhandari 2010; Aghai 2010].

This study showed that the length of hospital stay was shorter in the SNIPPV group, which might be associated with a lower extubation failure rate. The prevalence of VAP and mortality in the SNIPPV group were lower than those in the NCPAP group, but the difference was not statistically significant. This result might be related to the small number of subjects in the study. Due to the increased transpulmonary pressure, SNIPPV and NCPAP might lead to excessive lung expansion, so one should be aware of the possibility of pneumothorax. The present study showed no significant difference in the incidence of pneumothorax between the two groups. SNIPPV was a synchronized mode of NIPPV, which was closer to the infants' physiological state and theoretically could reduce the incidence of lung air leakage or pneumothorax. Jasani et al and Kahramaner et al indicated that the incidence of pulmonary air leakage in the NIPPV group was lower than that in the NCPAP group [Jasani 2015; Kahramaner 2014]. The possible digestive complications of noninvasive ventilation, such as gastrointestinal dilatation, feeding difficulties, and the risk of gastrointestinal perforation, had always been scholars' concern. Studies had shown that there was no significant difference in the feeding intolerance rate and incidence of gastrointestinal perforation between the NIPPV group and the NCPAP group during assisted 
Table 3. Primary Outcomes after Extubation

\begin{tabular}{|c|c|c|c|c|}
\hline \multirow[t]{2}{*}{ Extubation failure } & Hypoxemia, $n$ & 1 & 3 & .038 \\
\hline & Heart failure, $n$ & 0 & 1 & \\
\hline \multirow[t]{3}{*}{ After 1 hour of non-invasive ventilation } & $\mathrm{PH}$ & $7.34 \pm 0.04$ & $7.32 \pm 0.05$ & .085 \\
\hline & $\mathrm{PaCO}_{2}, \mathrm{mmHg}$ & $45.48 \pm 4.85$ & $49.09 \pm 4.43$ & .003 \\
\hline & $\mathrm{PaO}_{2} / \mathrm{FiO}_{2}$ & $228.75 \pm 38.60$ & $203.68 \pm 45.30$ & .010 \\
\hline \multirow[t]{3}{*}{ After 12 hours of non-invasive ventilation } & $\mathrm{PH}$ & $7.31 \pm 0.04$ & $7.29 \pm 0.05$ & .146 \\
\hline & $\mathrm{PaO}_{2}, \mathrm{mmHg}$ & $74.94 \pm 8.54$ & $63.65 \pm 6.99$ & $<.001$ \\
\hline & $\mathrm{PaCO}_{2}, \mathrm{mmHg}$ & $47.97 \pm 7.53$ & $52.68 \pm 8.41$ & .019 \\
\hline \multirow{2}{*}{ After 24 hours of non-invasive ventilation } & $\mathrm{PaCO}_{2}, \mathrm{mmHg}$ & $37.65 \pm 7.12$ & $42.74 \pm 8.05$ & .010 \\
\hline & $\mathrm{PaO}_{2} / \mathrm{FiO}_{2}$ & $251.68 \pm 51.39$ & $226.92 \pm 48.94$ & .035 \\
\hline \multirow[t]{4}{*}{ After 48 hours of non-invasive ventilation } & $\mathrm{PH}$ & $7.35 \pm 0.06$ & $7.33 \pm 0.08$ & .122 \\
\hline & $\mathrm{PaO}_{2}, \mathrm{mmHg}$ & $83.50 \pm 7.55$ & $74.51 \pm 5.12$ & $<.001$ \\
\hline & $\mathrm{PaCO}_{2}, \mathrm{mmHg}$ & $38.21 \pm 8.49$ & $44.26 \pm 9.51$ & .010 \\
\hline & $\mathrm{PaO}_{2} / \mathrm{FiO}_{2}$ & $248.03 \pm 53.86$ & $245.78 \pm 67.73$ & .400 \\
\hline
\end{tabular}

Data reported as number and percentage, mean \pm standard deviation, or median and interquartile range.

Table 4. Secondary Outcomes and Complications after Extubation

\begin{tabular}{|c|c|c|c|}
\hline VAP, n (\%) & $5(15)$ & $6(20)$ & .744 \\
\hline Mortality, n (\%) & $1(3)$ & $2(7)$ & .601 \\
\hline Pneumothorax, n (\%) & $3(9)$ & $5(2)$ & .462 \\
\hline Vocal cord paresis, n (\%) & $1(3)$ & $2(7)$ & .601 \\
\hline Feeding intolerance, $\mathrm{n}(\%)$ & $5(15)$ & $8(27)$ & .353 \\
\hline Gastroesophageal reflux, n (\%) & $4(12)$ & $7(22)$ & .325 \\
\hline Time to full gastrointestinal feeding after surgery, days (median, IQR) & $6.5(3.2-13.6)$ & $7.6(4.5-16.2)$ & .172 \\
\hline Duration of postoperative noninvasive support, days (median, IQR) & $2.3(1.3-4.5)$ & $4.0(2.8-6.6)$ & .013 \\
\hline Total hospital costs in $\$($ median $\pm S D)$ & $9790 \pm 3530$ & $12133 \pm 4582$ & .031 \\
\hline
\end{tabular}

Data reported as number and percentage, mean \pm standard deviation, or median and interquartile range. VAP indicates ventilator associated pneumonia; LOS, length of stay; IQR, interquartile range. 
ventilation [Jasani 2015; Khalaf 2001]. We also found no statistically significant difference in the incidence of feeding intolerances, gastrointestinal perforation, and gastroesophageal reflux between the two groups, which suggested that the side effects of SNIPPV on the digestive system were similar to those of NCPAP. Besides, our study showed that the postoperative length of hospital stay and the duration from extubation to hospital discharge were significantly shorter in the SNIPPV group than in the NCPAP group, leading to a significant difference in hospital costs between the two groups.

This study was the first study comparing post-extubation respiratory support with SNIPPV and NCPAP after congenital heart surgery in infants. The present study has several limitations. First, this was a retrospective and observational study that only intended to evaluate the post-extubation respiratory support modality's efficiency in infants who underwent cardiac surgeries requiring $\mathrm{CPB}$. It could not generalize the effectiveness of SNIPPV versus NCPAP to other pediatric patients in critical condition. Due to the small sample size of this study, further stratification analysis was not conducted according to the severity of pulmonary disease. Furthermore, for all of the infants, the clinical data were recorded until they were discharged from the hospital, and there was a lack of comparison of the results of long-term lung function, neurodevelopmental outcome, and other prognostic data. Finally, as a relatively new non-invasive ventilation technology, few relevant clinical studies were found in infants with CHD. This mode's safety and efficiency still need to be confirmed by prospective, multicenter, and large-sample studies in the future.

\section{CONCLUSION}

Compared with NCPAP, the application of SNIPPV is a safer and more effective mode for post-extubation respiratory support after congenital heart surgery in infants. SNIPPV could improve invasive mechanical ventilation extubation success in infants with CHD, significantly improve oxygenation, and reduce $\mathrm{PaCO} 2$ retention after extubation. At the same time, it does not increase the risk of ventilator-related complications. Future studies are needed to confirm the efficacy and safety of SNIPPV as a routine weaning strategy after congenital heart surgery.

\section{ACKNOWLEDGMENTS}

We are grateful to Bing Yang for his suggestions regarding the manuscript. We highly acknowledge the contribution of the participating researchers: Qi-Liang Zhang, Ze-Wei Lin, Li-Wen Wang, Jing Wang, and Ling-Shan Yu.

\section{REFERENCES}

Aghai ZH, Saslow JG, Nakhla T, et al. 2010. Synchronized nasal intermittent positive pressure ventilation (SNIPPV) decreases work of breathing (WOB) in premature infants with respiratory distress syndrome
(RDS) compared to nasal continuous positive airway pressure (NCPAP). Pediatr Pulmonol 41:875-81.

Badesch DB, Champion HC, Sanchez MA, et al. 2009. Diagnosis and Assessment of Pulmonary Arterial Hypertension. J Am Coll Cardiol 54(1 Suppl):S55-S66.

Barrington KJ, Bull D, Finer NN. 2001. Randomized trial of nasal synchronized intermittent mandatory ventilation compared with continuous positive airway pressure after extubation of very low birth weight infants. Pediatrics 107:638-41.

Benneyworth BD, Mastropietro CW, Graham EM, et al. 2017. Variation in extubation failure rates after neonatal congenital heart surgery across Pediatric Cardiac Critical Care Consortium hospitals. J Thorac Cardiovasc Surg 153:1519-26.

Bhandari V, Gavino RG, Nedrelow JH, et al. 2007. A randomized controlled trial of synchronized nasal intermittent positive pressure ventilation in RDS. J Perinatol 27:697-703.

Bhandari V. 2010. Nasal intermittent positive pressure ventilation in the newborn: review of literature and evidence-based guidelines. J Perinatol 30:505-12.

Chang HY, Claure N, D'ugard C, et al. 2011. Effects of synchronization during nasal ventilation in clinically stable preterm infants. Pediatr Res 69:84-9.

Chen L, Wang L, Ma J, et al. 2019. Nasal high-frequency oscillatory ventilation in preterm infants with respiratory distress syndrome and ARDS after extubation: A Randomized Controlled Trial. Chest 155:740-8.

Essouri S, Durand P, Chevret L, et al. 2005. Non invasive positive pressure ventilation (NIPPV) in PICU: a promising approach of respiratory support. Pediatric Critical Care Medicine 6:245.

Fedor KL. 2017. Noninvasive respiratory support in infants and children. Respiratory Care 62:699-717.

Gaies M, Tabbutt S, Schwartz SM, et al. 2015. Clinical epidemiology of extubation failure in the pediatric cardiac ICU: A report rrom the Pediatric Cardiac Critical Care Consortium. Pediatr Crit Care Med 16:837-45.

Gaies MG, Gurney JG, Yen AH, et al. 2010. Vasoactive-inotropic score as a predictor of morbidity and mortality in infants after cardiopulmonary bypass. Pediatr Crit Care Med 11:234-8.

Harris KC, Holowachuk S, Pitfield S, et al. 2014. Should early extubation be the goal for children after congenital cardiac surgery? J Thorac Cardiovasc Surg 148:2642-7.

Jasani B, Nanavati R, Kabra N, et al. 2015. Comparison of non-synchronized nasal intermittent positive pressure ventilation versus nasal continuous positive airway pressure as post-extubation respiratory support in preterm infants with respiratory distress syndrome: a randomized controlled trial. J Matern Fetal Neonatal Med 29:1546-51.

Kahramaner Z, Erdemir A, Turkoglu E, et al. 2014. Unsynchronized nasal intermittent positive pressure versus nasal continuous positive airway pressure in preterm infants after extubation. J Matern Fetal Neonatal Med 27:926-9.

Khalaf MN, Brodsky N, Hurley J, et al. 2001. A prospective randomized, controlled trial comparing synchronized nasal intermittent positive pressure ventilation versus nasal continuous positive airway pressure as modes of extubation. Pediatrics 108:13-17.

Lemyre B, Davis PG, De Paoli AG, et al. 2017. Nasal intermittent positive pressure ventilation (NIPPV) versus nasal continuous positive airway pressure (NCPAP) for preterm neonates after extubation. Cochrane Database Syst Rev 2:CD003212. 
Lu C, Wei J, Cai B, et al. 2020. Etiology and risk factors for extubation failure in low birth weight infants undergoing congenital heart surgery. J Cardiothorac Vasc Anesth 34:3361-6.

Parashar N, Amidon M, Milad A, et al. 2019. Noninvasive neurally adjusted ventilatory assist versus high flow cannula support after congenital heart surgery. World J Pediatr Congenit Heart Surg 10:565-71.

Polin RA, Sahni R. 2002. Newer experience with CPAP. Semin Neonatol 7:379-89.

Richter RP, Alten JA, King RW, et al. 2019. Positive airway pressure versus high-flow nasal cannula for prevention of extubation failure in infants after congenital heart surgery. Pediatr Crit Care Med 20:149-57.
Sai Sunil Kishore M, Dutta S, et al. 2009. Early nasal intermittent positive pressure ventilation versus continuous positive airway pressure for respiratory distress syndrome. Acta Paediatr 98:1412-5.

Tao HF, Tao M, Cai N, et al. 2016. Apllication of nasal synchronous intermittent mandatory ventilation in premature infants with severe respiratory distress syndrome after extubation. Zhongguo Dang Dai Er Ke Za Zhi 18:1-5.

Zhou B, Zhai JF, Jiang HX, et al. 2015. Usefulness of DuoPAP in the treatment of very low birth weight preterm infants with neonatal respiratory distress syndrome. Eur Rev Med Pharmacol Sci 19:573-7. 